\title{
Reform of Interactive Design Undergraduate Course System in Chinese Universities
}

\author{
Dandan Zheng \\ College of Art and Media \\ China University of Geosciences(Wuhan) \\ Wuhan, 430074, China
}

\begin{abstract}
Facing the rapid development of information society and the urgent needs of the Internet industry, colleges and universities have set up interactive design specialty one after another. How to improve the quality of training interactive design professionals and how to make the teaching of interactive design professionals meet the needs of the creative industry at present. This paper summarizes and analyzes four major problems existing in the current teaching of interactive design specialty: unreasonable curriculum structure, single teaching mode, confused curriculum logic and no professional atmosphere And in view of the above situation, we find out several solutions, such as curriculum construction, specialty blending, schoolenterprise cooperation and so on. We hope that we can further explore the teaching of interactive design specialty and find a more ideal teaching mode.
\end{abstract}

Keywords-undergraduate major; interaction design; curriculum reform; problems; suggestions

\section{INTRODUCTION}

In the face of the Internet and the background of interaction design, the employment market demand is fundamental. However, there are some problems that need to be solved in the current teaching, which need to be seriously considered and solved, so as to facilitate the interactive design of professional training programs and meet the needs of the future development of society.

With the advent of the information age, products become more and more complex. Engineers and designers take it for granted that design leads to serious consequences, that is, users will be at a loss when facing the product, seriously affecting the user's experience when using the product, and even hindering the normal use of the product.[1] Every school has its corresponding teaching plan, but it is undeniable that interactive design courses are generally related to computer hardware and software knowledge. Through exploring the courses of interactive design specialty in recent years, it is found that the training and output of talents nowadays are far from meeting the needs of society, and there is no way to guarantee the quality and professional quality of talents exported. The reason is that the art students' own level is uneven, and the form of teacher's classroom teaching is relatively single, which does not give full play to the initiative and innovation of students. The evaluation mechanism of judging students' comprehensive ability by scores frustrates the enthusiasm of learners, and the method of grading training is

Fund Project: School-level Teaching Research Project Item Number: 2017A38 difficult to achieve. In this paper, a series of discussions are carried out on the arrangement and setting of the syllabus, the curriculum, the construction of the teaching staff, and whether the teaching content meets the needs of employment.

\section{ANALYSIS OF PROBLEMS AND REASONS IN THE TEACHING OF INTERACTIVE DESIGN SPECIALTY}

In view of the present situation in the teaching of interactive design specialty, the reasons are not simple and uniform. There are not only objective reasons such as unreasonable curriculum structure and teaching, but also subjective reasons such as the limited level of teachers and the need to improve the quality of teaching. Here, the author summarizes the following four aspects:

\section{A. Unreasonable Course Structure}

How to cultivate and improve undergraduate students' practical computer technology skills, improve students' problem-solving ability and self-learning ability, and cultivate students' innovation and entrepreneurship ability has become an important issue in the cultivation of Applied Talents in Colleges and universities.[2] At present, theoretical courses account for a large proportion in the teaching of interaction design in the Internet + background. Teachers rely on textbooks to explain, and the practice links are seriously inadequate. Students sitting in the classroom listening to hieroglyphic or they are absent-minded. Even if the theory class is full of words, the result is that they can't do anything by hand, and they can't convert input into output. Indeed, the study of theoretical knowledge plays an effective role in guiding practice on the one hand, and on the other hand, it is also a key link to improve the cultural literacy of College students. The undergraduate education is to train applied talents, which should have a reasonable proportion of computer software type of practical courses. In the undergraduate talent training program of our university, it is clearly stated that reducing the teaching hours of teachers in class, dividing the course hours into the teaching hours of teachers in class, the scientific research practice hours and the quality development hours, so as to guide students to study independently. In the teaching research of universities which are in the leading position in the field of interactive design in China, it is found that interactive design teaching lays more emphasis on practicality and interdisciplinary attributes.[3] Especially in the design courses of interactive design major in universities, we need to master 
the software application methods and skills of the interactive design discipline in the Internet + background. More teaching time should be devoted to practice. If students can't master the operation skills of software and hardware skillfully, it will also be fatal for the study of other courses in this major and the final product landing.

\section{B. A Single Teaching Model, No Practical Teaching System}

Nowadays, in the face of the rapid development of information technology, Internet popularization and smart phones, computer software and hardware education curriculum has penetrated into all areas of social life. The emergence and application of flipped classroom has promoted the reform and innovation of traditional teaching mode, and has also aroused widespread concern in the educational circles.[4] Under the teaching mode of flipping classroom, students can learn knowledge by means of pre-class micro-video or other teaching resources. As far as micro-video is concerned, teachers record and upload micro-videos for 3-20 minutes that need to be explained in class to the online teaching platform, so that students can watch them online. Anti-dragging and focus locking techniques are used to ensure that students can watch videos effectively. In videos, teachers can also insert questions or tests to achieve effective learning. [5]This kind of teaching mode has just started in our college, but it is enough to prove that mobile learning and online-offline collocation teaching mode are effective measures to adapt to the current information-based teaching. It can't only enhance the learning effect, improve students' self-study ability and cooperation ability, but also in classroom teaching, teachers can more effectively extract the key and difficult points of each part. More detailed explanation of the breadth and depth of knowledge and its true realization of teaching are based on students' self-study, breaking the traditional teaching model instilled by teachers. For example, computer-aided design course, 48 hours, mainly involves two software: Photoshop and illustrator. In class, students are found to have uneven software foundations and are particularly tired at the beginning of the lecture. Some students have never even opened the software, and some students can draw some simple pictures. From the realization of proficiency in operation, it is by no means possible to achieve 48 hours. In addition, besides explaining how to operate and use the software, the class also involves how to design the products of some basic interactive design directions. The difficulty coefficient is conceivable. Finally, due to time constraints, the works are also rough. If we carry out online video self-study in advance, pay attention to practical teaching, emphasize the ability of students to solve practical problems themselves, and fully mobilize students' initiative and enthusiasm in learning. Then, with the help of the class, throwing out the current hot topics, the students gathered their brainstorming ideas and then clicked on the students to make statements on the stage. Every student has his own depth of knowledge, so the way to solve and elaborate the problem will show diversity and profundity, and the students on the stage will unconsciously measure whether they will answer like this or what kind of knowledge they are in. So the teaching effect is totally different.

\section{Unreasonable Course Order}

The curriculum system refers to the arrangement of different courses in the same specialty according to the category order, which is the sum of teaching content and process. The arrangement order of courses determines what kind of knowledge structure students will acquire through learning.[6] In the past two years, the courses of interactive design and digital animation specialty are in one system, and their respective curriculum systems are constructed. Due to the lack of communication and communication among the teachers of interactive courses, and the uniqueness of the major itself, some of the contents have already been mentioned, but the teachers in the following class do not know, and then they teach the repeated contents. The content of interactive design course is not well connected in width and depth. It causes students to learn some professional knowledge repeatedly, and it also causes waste of teaching resources.

Throughout the syllabus arrangement of Interactive Interface Design major in major universities, the sequence of courses is confused. There are many disputes about the order of curriculum arrangement of Interactive Interface Design, such as whether User Research, Interaction and Experience, Information Architecture and Interactive Design Method should be before Interactive Interface Design, [7] which has been clearly explained in this table. We can look at the fourth tier of the framework: interface design, navigation design and information design. In the conceptual structure layer, a large number of needs have been formed, which come from our strategic objectives. This shows that "Interactive Interface Design" is a course that should be arranged behind them. By planning the information structure of the product and formulating the interactive design method, the prototype of the interface can be drawn. Project planning is an art that requires vision and the ability to think along parallel timelines. The tasks that need to be undertaken in the process of user experience design need to be overlapped in other tasks at the same time. User research, stakeholder analysis, user modeling and other activities can be overlapped in most projects. Identifying tasks that will delay the project if they are not completed on time is a good idea. For example, the wireframe of the internal structure of the visual interface needs to integrate the functional elements of the design. This means that the creation of the wireframe needs to be done on the premise that the functional specifications are ready. [8]First of all, it should be User Research, which defines the user's needs and the functions and design points of the system. Next, Interaction and Experience runs through the entire project process, but introductions can be introduced in sophomore courses. After that, we use the method of user experience to develop products through specific projects. Then it is Information Architecture and Interactive Design, which must be before Interactive Interface Design. Information structure is the mode of organizing information. Individual information is linked through different structures to form an interface that can accomplish a certain function.[9] The information structure here is also the information architecture, so it is very clear and clear. 


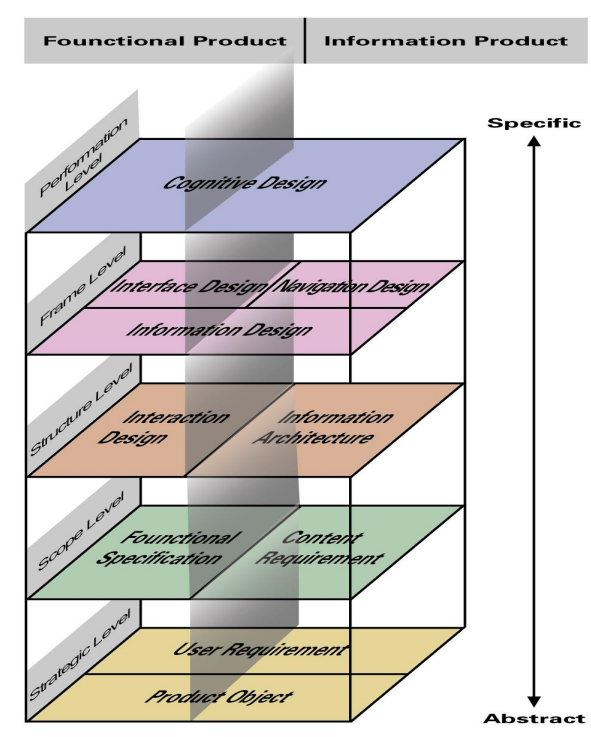

Fig. 1 The five elements of user experience

\section{Lack of Professional Atmosphere}

Atmosphere refers to the special atmosphere or mood that surrounds a particular occasion. Emotion refers to the basic characteristics of emotion. Psychologically, it usually refers to the emotional tone of sensation and perception, that is, the emotional experience associated with sensation and perception.[10] Each profession has its own unique charm, which can stimulate the audience to a certain degree of appeal. The artistic atmosphere can also be called artistic sentiment. In the art and Media Institute where the author live, there is a lack of this kind of design atmosphere. Especially in the direction of interactive design, students are still addicted to traditional easel painting after 2 or 3 years in university. After learning computer-related courses, they are still useless. They have not applied the aesthetic skills and aesthetic viewpoints in painting to design practice, resulting in students failing to achieve the goal of training design professionals in Colleges and universities. There are two reasons for this: First, the hardware facilities are not in place. For the new professional direction of interactive design, without these equipment conditions, the professional atmosphere is impossible to talk about. Secondly, the change of students' thinking concept should be more important. It should gradually guide students to engage in relevant professional studios, lead them to do some research projects, carry out some practice and exploration so as to arouse their interest. Guangzhou Academy of Fine Arts has gone further and earlier in the direction of interaction design specialty. They divide the four-year undergraduate teaching task into two stages: design basic teaching stage and professional studio teaching stage. From this we can see that these studios are driven by the teaching concept of "subject system" to organize and implement teaching and scientific research topics. To set up a topic by oneself and cooperate with industry, we should take "putting it into practice, putting it into practice, putting it into practice, putting it into practice" as the guideline of setting up a topic by oneself.

\section{SUGGeStions For IMPROVEMENT}

The author enumerates the shortcomings in the teaching of interactive design in colleges and universities under the background of Internet + , and analyzes the reasons for the formation of the problem. Here, the author proposes the following suggestions for improvement:

\section{A. Strengthening the Integration of Interactive Design Specialty and Related Specialty}

Preface to Lou Yongqi, Dean of School of Art and Creativity, Tongji University, Shanghai: "In the past hundred years, design has undergone a paradigm transformation from "creative style" to "driving innovation". On the one hand, the roles, missions, methods and tools of design are undergoing tremendous changes. The objects of design have also been extended to the design of relationships, interaction, services, systems, organizations and mechanisms. On the other hand, design has expanded from one link of the industrial chain and innovation chain to the contributors of the system and the whole process. The theoretical research and discipline construction of Internet + interaction design should be closely related to the visual design, product design, and environmental art design. Through visits and surveys, in the interactive design teaching of MIT laboratories abroad, Carnegie Mellon University in the United States and Delft University of Technology in the Netherlands, students can carry out multidisciplinary subject research, which can greatly improve their professional ability. At present, the teaching of interactive design is in the forefront in China, such as the Academy of Fine Arts of Tsinghua University, the Nanjing Academy of Art, and the School of Design Creativity of Tongji University in Shanghai. They emphasize the close cooperation of different professional directions to achieve real cross-border. Students explore the frontier trend of future interactive design direction by reading a lot of literature and watching online videos. At the same time, they have also strengthened their close cooperation with universities around the world to jointly develop Workshop on the direction of interactive design.

\section{B. Strengthening the Close Cooperation between the Specialty and the Enterprise}

When choosing school-enterprise partners, design majors should first consider how to make the advantages of University talents, scientific research and other resources serve enterprises and produce benefits. Enterprises can provide teachers and students with practical projects and environment for teaching and scientific research, through complementary advantages of both sides, in-depth joint training of talents and build a platform for sharing and co-construction.[11] Employmentoriented training of applied college students is our teaching goal, and the combination of school and enterprise is an important link. Because only through close cooperation with enterprises, can we know the type of talents needed by enterprises so that we can achieve a definite goal in teaching principles and objectives. With the development and popularization of the Internet, the demand for computer talents from five Internet giants, such as Alibaba, Baidu, Tencent, Jingdong and Netease, has directly stimulated the cultivation and output of interactive design talents in universities, such as 
interactive experience designers, UI designers, web designers, Java development engineers and user researchers.

On the other hand, business managers and designers with industry experience are invited to teach practical projects. Nowadays, the definition of jobs is very fine and the functions of each job are very standard. It is obviously difficult for teachers in schools to maintain the standard of specialization in both fields. Therefore, it is also feasible to take students to practice in enterprises. However, practical projects here do not necessarily require real projects from society or enterprises. The premise is to select the training projects with high standard and standardized operation under the background of "Internet $+"$ according to the principles and objectives of training professionals in interactive design.

\section{Strengthening the Construction of Interactive Design Professional Teachers}

As far as the composition of interactive design professional team is concerned, there are fewer people, and most of the teachers are not from this direction, or from graphic design, digital animation, computer specialty, etc. They teach through their own constant exploration and accumulation. Teachers must realize that under the background of Internet + , teaching methods and roles need to be changed. Specifically speaking, it is to use the advantages of modern information technology to change the traditional single teaching mode and adopt the mixed teaching mode. The task of teachers becomes to stimulate students' interest in learning and to become helpers and promoters of students' learning. All these need to strengthen the training of teachers, participate in interactive design meetings, understand industry trends, and absorb more advanced teaching experience.

In a word, the teaching methods and modes of interactive design specialty need to be advanced to a higher level. With the continuous development of Internet technology, the reform of its teaching mode is imperative. In the future, the requirements of interaction Designers' professional competence and the subject background will be more diversified, and a teaching system of interaction and integration between disciplines will be formed. In this case, students and schools will inevitably put forward higher requirements for teachers.

\section{REFERENCES}

[1] Li Honghai, Shi Shuang, Li Xia: Interactive Interface Design, Chemical Industry Press, 2016 edition, p. 2.

[2] Ye Zhiwen, Computer Teaching Method [J]. Scientific Consulting (Educational Research), 2007 (6): 46-47.

[3] Bian Kun, Research on the Construction and Teaching Model of Interaction Design[J].Art Science and Technology,2014(11):203-203

[4] Fan Wenxiang, Ma Yan, Li Kai, et al. The Practice of Flipping Classroom Supported by WeChat in Mobile Learning Environment[J]. Open Education Research, 2015(3): 90-92.

[5] Tong Lei, Explore How to Use the Flip Classroom to Optimize College Classroom Teaching [J]. Contemporary education practice and teaching research, 2011.04.02

[6] Han Hongbin, Research on the Reform of the Teaching Content System of the Basic Courses of Design Majors in China $[\mathrm{J}]$, Beauty and Times(I)2017.12

[7] (US) Jesse James Garrett, Fan Xiaoyan, "User Experience Elements", Mechanical Industry Press, 2016 edition, p. 27.

[8] [English] Gavin Elinwood, Peter Bill, edited by Kong Xiangfu, Lu Rongxue, "International Classical Interactive Design Tutorial User Experience Design", Electronic Industry Press, 2015, p. 123.

[9] Li Honghai, Shi Shuang, Li Xia: Interactive Interface Design, Chemical Industry Press, 2016 edition, p. 31.

[10] Affirmation, From the Atmosphere to Cut Into the Interior Space Design [J]. Higher Architectural Education, 2014.

[11] Ma Changyong, Thinking about the Reform of the Application-oriented Talent Training Mode of the Design Course "Full-course dual-element" [J], Art Education Research, 2011.02: 153 